\title{
Correction to: Subnational climate entrepreneurship: innovative climate action in California and São Paulo
}

\author{
Karen Anderton $^{1}$ • Joana Setzer ${ }^{2}$
}

Published online: 30 October 2017

(C) Springer-Verlag GmbH Germany 2017

Correction to: Reg Environ Change (2017)

https://doi.org/10.1007/s10113-017-1160-2

In the published online version, the author missed to acknowledge the financial support from Grantham Foundation for the Protection of the Environment and the ESRC via the Centre for Climate Change Economics and Policy. The full, corrected Acknowledgement section is provided below.

Acknowledgements Our warm thanks to the participants at the Policy Entrepreneur Workshop (Amsterdam, May 2015) and particularly Dave Huitema, Andy Jordan, Elin Lerum Boasson and Raoul Beunen for the very helpful comments to earlier versions of this manuscript. We are also grateful to the two reviewers from Regional Environmental Change for their constructive comments. Joana Setzer acknowledges the financial support from the Grantham Foundation for the Protection of the Environment and the ESRC via the Centre for Climate Change Economics and Policy".

The online version of the original article can be found at https://doi. org/10.1007/s10113-017-1160-2

Karen Anderton

karen.anderton@ouce.ox.ac.uk

1 OUCE, University of Oxford, South Parks Road,

Oxford Oxon OX13QY, UK

2 Grantham Institute on Climate Change and the Environment, LSE, London, UK 